\title{
TURISMO DE EVENTOS \\ o Caso do Centro de Convenções da Bahia
}

\author{
Guilherme Marback Neto'
}

RESLing(): Na evolução do turismo de eventos no listado da Bahia, o Centro de Eonvenções da Bahia constitui um marco. Suscitou interessea insestigaão sobre o provivel papel deste Centro de Convençōes (implantado em 1978) na ;azonalidade do turismo de eventos local. () resumo revela entretanto (pus o Eentro de Convençōes da l Bahia não vem cumprindo plenamenteseu papel. l 'm tos itens quema is temcontribuido para isso é a influència das politicas publicas : a falta de profissionalizą̧ão na árca.

'ALAVRAS-CIIA VI:: T'urismo de eventos; Centro de C'onvençōes da Bahia; balvador; Bahia; Brasil.

1BSTRACT: Bahia's Conventions Center is a turning point in the evolution 'f convention Tourism in Bahia State. That fact gave rise to a research ahout he potential role of the ('enter (settled in 1978) in the seasonality' of local convention Tourism. The available data reveal, nevertheless, that the Center is not playing its role. One of the main motives for that to happen is the influence of public policies and the lack of professionalization in the area.

KEYHORLS: Convention tourism: Bahia's ('onventions ("enter: Salvador: Bahia: Brazil.

\section{INTRODUÇÃO}

Entre os importantes marcos da cxistência humana. situa-se a fixação dos rocais de moradia. Geralmente, é aquele que concilia toda ordem de necessidades, permanentes ou temporárias. Fixado o local de moradia, outra necessidade to homem é o deslocamento: por trabalho ou lazer. Esse deslocamento emporário, que se denomina turismo. passou a ser uma fonte de divisas para Palses e Estados. cujas politicas promocionais incentivaram o homem a. sempre

\footnotetext{
I Mestre en Administração pela Liniversidade lederal da Bahia. Prolessor da Faculdade de Comunicação Sallädor da Liniversidade Católica de Salvador.

End. para corresp.: Rua Pedro L.essal. 24 - 4)15()-360) - Salvador - Bahia - Brasil.
} 
que possível. ampliar o conlıccimento de sua cultura c a de outros por.os. Apesar de ser unla atividade antiga c com tantos significados, ainda há muria dificuldade coll considerí-la como um fator de desenvolvimento econômico. Esle estudo é motivado pela análise do turismo de er entos como ativ idade econômica c de lazer. o que muitos consideram como mutuamente crclusiva. Apropriadamentc. KRIPPENDORF ( 1989 ) refere-se a esla questiăo relatando que

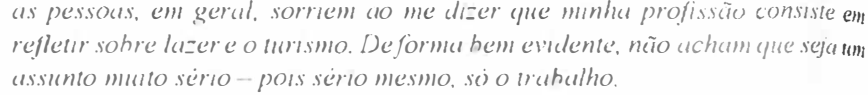

No Brasil, somente em 1966, com a criação da Empresa Brasileira de Turismo (EMBRATUR)2 . o lurismo passou a ter cunho oficial. Apesilr disto, ainda sĩo poucos os traballıos e publicações cientificas nesla área

\section{TURISMO DE EVENTOS}

Esı tipo não-convencional de turismo caracterizal-se pela realização de feiras. congressos, convenções e festas populares. Esta conceituaão cra dada principalmente às feslas populares. COVELLO(1982) refere-se a esla modalidade afirmando que:

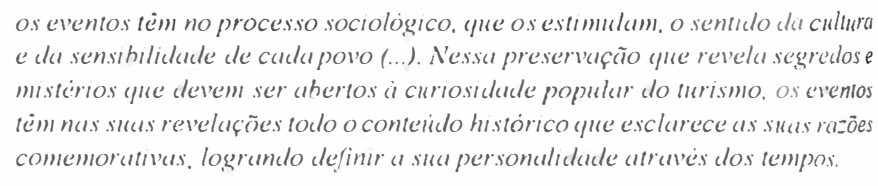

os eventos tèm no processo socrológico, que os est imulam, o sentudo da culture

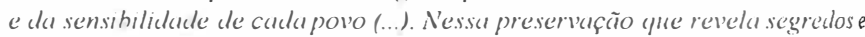
misterios que devem ser ahertos a currosiducle popular do urrismo, os éventos

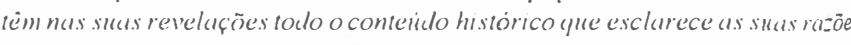
comemoratrves. logrando definur a sua personaldedude atraves dos tempos:

As feiras c c.yposições, com grande repercussiõo no lurismo. ja fìzem parte do lurismo de negócios. Este tipo de ciento tem sua origem nas feiras da Idade Média. Hoje. a necessidade de cxpor e conhecer novos produtos é uma priticia que faz parte dos negócios. É o resultado do crescimento de delerminiados locilis. TABARES (1986) ressallia. dentre outras vantagens do lurismo de congressos. a de senir para solucionar. cm parte. a sizonalidade do turismo. porque geralmente ocorre em épocias de baika estaçĩo. periodo em que se pode formecer melhores serviços e tarifas promocionais.

O diretor superintendente do Centro de Conrenções da Bahia. nia ćpoca de sua implantaçĩo. declarou ao jornal Cinzeta da Bahira a importinncia do Turismo de Eventos. dizendo

2 Hoje. o atual Instituto Brasileiro de Turismo.

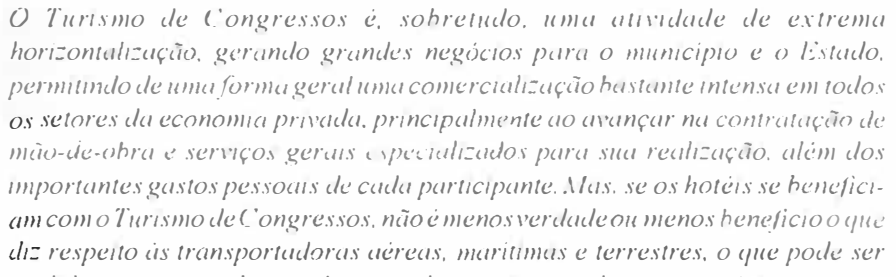

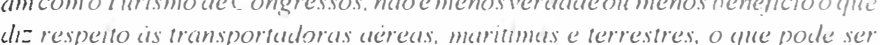
medido proporcionalmente is taxas de crescimento dos sens. numuirios.

Os destinos, as cidades. os Eslados ou alć os países receptores sĩo os que têm maior possibilidade de retorno dos negócios. É com esla concepção que os governos costumam investir. financiar c apoiar a consınıçĩo de Centros de Convenções. Na maior parte do mundo. os Centros de Conrenções sĩo deficitários e seu maior objetivo restringe-se a alrair turistas congressistas para a localidade.

Para todo Centro de Convenções c lambém para o Turismo de Eventos. a realização de erentos intcrnacionais ć o que realmente contribui para o aumento do PIB locial. pois, além de trazer turistas (congressislas), faz cntrar moeda de valor no mercado internacional. aumentando as divisas nacionais. No rabalho Anteprojete sobre lercade Internacienal de fientes (BAHIATURSA. 1981) há a apresentaçĩo de dados de um relatório. realizado pela Internacional Marketing Scrvice, no qual se estima que. a preços de 1978. um delegado gasic aproximadamente US\$ $\$ 3.5$ por erento atcndido. Cercal de $1.5 \%$ a a $3.5 \%$ derem ser adicionados a esse valor quando ao delegado se juntam acompanhantes (esposa, fillos c outros). O gasto de US\$ $\$ 5.3 .5$. cm dinheiro cm 1978, $1 \mathrm{~cm}$ a seguinte distribuição aproximada:

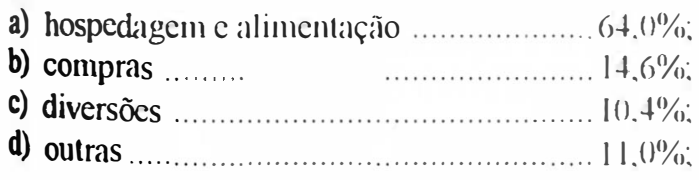

O turista congressista lem um perfil especial: fica menos tempo e gasta mais. Além disso. cle visila a cidade em épocal de baival eslação. ABBEY (1 1987) reforça csla obsenaçĩo quando afirma que

os purticipantes de conferincias se encontrum, dormem e fuzem refécicenes soho mesmo teto.

Apesar de se ter consciência da importância de unı crento. o Brasil. em 1990, de acordo com a Uniäo de Associações Internacionais (UIA). ocupou o $16^{\circ}$ lugar no ranking mundial de países que realizam congressos internacionais. Este 
declínio (uma vez que ocupou posições melhores) deve-se principalmente à fal ta de investimento no setor, pois a grande preocupação do setor público é passar a pertencer ao grupo de países desenvolvidos através de um único modelo: a lı10. suficiência em indústrias.

Pode-se considerar que, para uma melhor captação de Congressos. se torna importante preencher dois requisitos básicos: infra-estrutura turística infra-estrutura urbana. E claro que a segunda inclui a primeira, mas deve-se considerar ambos os requisitos isoladamente, mesmo quando se entende 0 primeiro como equipamentos de turismo (hotéis, restaurantes, agente de viagens etc.) e o segundo como transporte urbano, aéreo, energia, saneamento básico, comunicações etc. Embora com todo este aparato, ainda há outros fatores que interferem no trabalho de captação de um Centro de Convenções.

Na Espanha, o estudo realizado pelo Ministério de Transportes, Turismo $y$ Comunicaciones (1985), abordou detalhes importantes:

a) geralmente se faz um investimento alto nas construções dos Centros. No entanto, destina-se muito pouco para uma adequada promoção

b) os Centros têm pouca flexibilidade na aplicação de tarifas, sendo mais difícil competir com o restante das salas;

c) na construção de Centros deve-se levar em conta a execução de congressos pequenos e médios. Isto melhoraria a ocupação e até a facilidade de realizar vários eventos simultaneamente. $\mathrm{ABBEY}$ (1987) considera que há duas tarefas para garantir a convenção. Uma é a de vender e fazer o marketing da sua comunidade e criar facilidades. A outra é servir ao grupo dispensandothe o que fora prometido. A primeira tarefa está vinculada ao momento chamado captação de eventos. Já a segunda, torna-se uma das principais preocupações pela sincronia que deve existir entre o "captador de eventos" e “organizador de cventos", que nem sempreé o mesmo. Quandoovisitante chega ao local, quer encontrar tudo o que foi combinado. Para captar eventos de forma mais organizadae até sistemática algumascidades do mundo (Paris Londres, Nova York) criaram os "Convention Bureau". Estes organismos geralmente são ligados ao sistema de turismo local, mas atuam coml independência levando em consideração as condições e necessidades do destino. No Brasil temos o São Paulo Convention and Visitors Bureau co Rio Convention Bureau.

Outra questão importante para realização de eventos éa formação de mãode-obra especializada que se torna imperativa para o aumento da qualidade do serviços. No Brasil ainda não há um curso específico, mas em outros países isto já acontece, como, por exemplo, no Canadá.

\section{TURISMO NA BAHIA}

3.1 Considerações Gerais

Num estudo realizado pela EMBRATUR, citado por BURMAN e PROSÉRPIO (1989), constatou-se que,

depois do Rio de Janeiro, a Bahia constitui o principal local que as pessoas gostariam de conhecer e ainda não conhecem.

O grande potencial para o incremento do turismo dessa região é confirmado no item "locais onde pretende viajar", em que a Bahia situou-se em $3^{\circ}$ lugar, com 39\% das indicações.

Apesar de possuir belezas naturais no nordeste e centro-oeste do Estado, é no litoral que o Turismo é mais desenvolvido; inclusive as cidades do sul do Estado, como Porto Seguro e Ilhéus, são as maiores fontes de receitas. Mesmo com grande potencial c em posição privilegiada no território brasileiro, Salvador, e conseqüentemente a Bahia, vem perdendo posição no ranking brasileiro de Estados mais visitados. Confirmando esta situação,a Tabela 1 mostra como o turismo caminha com instabilidade e decréscimo na Bahia.

Tabela 1 - Evolução do Fluxo Turístico Global (Salvador, 1981-1988)

\begin{tabular}{|c|c|c|}
\hline Anos & $\begin{array}{c}\text { Turistas } \\
\left(\mathbf{n}^{\circ}\right)\end{array}$ & $\begin{array}{c}\text { Crescimento } \\
(\%)\end{array}$ \\
\hline 1981 & 824.150 & - \\
\hline 1982 & 838.316 & 1,7 \\
\hline 1983 & 959.560 & 6,2 \\
\hline 1984 & 1.019 .131 & 6,4 \\
\hline 1985 & 1.083 .933 & 23,6 \\
\hline 1986 & 1.340 .132 & $(8,6)$ \\
\hline 1987 & 1.224 .413 & $(12,0)$ \\
\hline 1988 & 1.077 .800 & \\
\hline
\end{tabular}

Fonte: BAHIATURSA 
O Turismo institucional na Bahia teve início na década de 1030 , criação do Departamento Municipal de Turismo (DMT), vinculado à Prefeitur a da cidade de Salvador com atribuições restritas à área metropolitana

Em 1953, a Prefeitura dava outro passo para o desenvolvimento do Turismo em Salvador, criando, através da lei n. 410, o Conselho de Turismo do cidade de Salvador, c a Diretoria Municipal de Turismo. Somente em 1958 quando a Fundação Comissão de Planejamento Econômico (FCPE) incluiu, Turismo entre os capítulos do Programa do Estado da Bahia, o poder público estadual começou a participar da área turística.

No governo Luiz Viana Filho, em 28 de agosto de 1968, foi criada a BAHIATURSA - Hotéis de Turismo do Estado da Bahia. Segundo a lei n. 2563, art. $2^{\circ}$, esta organização tinha como atribuições:

a) construir e estimular a construção ou adaptação de hotéis, motéis e pousadas de interesse turístico no Estado da Bahia;

b) reformar e ampliar as instalações e serviços de hotéis de Itaparica c Cipó, dando-lhes condições adequadas ao desenvolvimento do turismo naquelas instâncias hidrominerais.

A criação da BAHIATURSA veio confirmar as necessidades detectadas no I Encontro Regional do Recôncavo para o Desenvolvimento do Turismo, realizado em janeiro de 1967, em Cachoeira, no qual o objetivo foi discutir sobre a estrutura do turismo no Recôncavo Baiano. Com o crescimento do turismo e suas múltiplas atribuições, a BAHIATURSA, em 11 de outubro de 1976, cria uma subsidiária, a Empreendimentos Turísticos da Bahia S. A. (EMTUR), cuja atribuição era a "construção, ampliação, reforma e reconversão de hotéis c outros meios de hospedagem no interior do Estado". Ainda fazendo parte do crescimento do Sistema de Turismo na bahia, é criada em 1977, através da lei n. 3.575, a Empresa Bahia Convenções S.A. (CONBAHIA), responsável pela administração do Centro de Convenções da Bahia, inaugurado em 1978

Hoje, o Sistema Estadual de Turismo é formado apenas pela BAHIATURSA, que absorveu as atribuições dos outros dois órgãos extintos.

\subsection{O Centro de Convenções da Bahia}

Apesar do Centro de Convenções da Bahia (CCB) ter sido criado somente em 1978, desde o governo Juraci Magalhães (1935-1939) jil so cogitava a implantação de um centro de convenções. Nesse governo, chegolse a planejar uma sede com pavilhões para exposições, conferências e outros tipos de eventos. Este plano foi concebido em função da criação da Ala das Letras e das Artes (ALA), em 1937.
No governo de Otávio Mangabeira (1947-1951), houve um grande apoio imento cultural do Estado, através de apoio financeiro do governo. zodesenvolu co dinamizado através da convocação de congressos nacionais e Este processo cra da cultura baiana. Desta forma, mesmo antes de possuir o seu da valorizaçano da Convenes, a cidade de Salvador já era procurada por inúmeras Centro de Conves entidades, para a realização de eventos.

associações de classe 70 , essa procura se deve principalmente ao crescimento do $\mathrm{Na}$ década de 70, essa procura se deve principalmète vocação turística hotelciro, à quantidade e qualidade dos leitos eà fortc vocaçáo turistica parque ho. Em 1975, por exemplo, registraram-se 48 eventos com a media de 713 dacidade. Em por evento. Em 1976, esta média passou a 52 eventos com 948 participantes Nesta época era unânime a falta de um equipamento com grande participantes. Ncsta cpoca cra unanimea ala de un cén capacidade, apropriado para eventos maiores, como amómero d participantes dade de cventos $\mathrm{c}$ até um local que abrigasse um maior número d participantes,

O Plano do Recôncavo, elaborado em 1970, propiciou a tomada de rovidências. cm 1975, para dotar Salvador de um local específico para congressos, feiras e convenções. Logo após a determinação do local onde seria congress, Centro, fez-se a concorrência nacional para escolher o melhor anteprojeto arquitctônico para a execução da obrà

O prédio construido comporta auditórios, áreas para exposição, bares, lojas, restaurantes e serviços de apoio, "bureau" de informações, comunicações e serviços auxiliares. Os auditórios podem ser usados de forma flexível, com 2.500 lugares num só salão e 600 lugares em outro, como também seccionados e transformados $\mathrm{em}$ quatro grandes auditórios.

Hojc, após a reforma que custou cerca de 15 milhões de dólares, o Centro está com outra apresentação:

a) houve a recuperação da estrutura metálica, fachada, piso, acústica, ar condicionado, instalação elétrica, telefônica e hidráulica;

b) oquarto paviment o foi todo modificado e passou a ter 22 salas e 6 auditórios A grande vantagem passou a ser a flexibilidade destes espaços por serem todos modulados;

c) no foyer do Auditório Yemanjá foram instalados uma sala VIP, um coffee bar e uma Ccntral de Informações;

d) no tercciro e segundo andares, o piso original foi substituído por outro de alta resistência com acabamento em granito.

No cntanto, o grande avanço para captar novos eventos foi a implantação do Pavilhão de Feira e Exposição, numaárea de $12 \mathrm{mil} \mathrm{m}^{2}$, com capacidade para aproximadamente 150 estandes.

Segundo dados da EMBRATUR, Salvador chegou a ocupar o $3^{\circ}$ lugar em turismo de congressos, sendo superado apenas pelo Rio de Janeiro e São Paulo Em 1989. passou para a 6 a colocação, junto com Curitiba, antecedendo-se o Rio de Janeiro. São Paulo, Porto Alegre, Fortaleza e Foz de Iguaçu. 
Na tabela 2. verilical-se a situaçĩo da Bahia no turismo de congressos cm relaçĩo aos outros Estados brasileiros. O número de eventos internacionatis no Brasil foi fornecido pela EMBRATUR. incluindo acompanhantes no número de participantes dos erentos. O número de erentos na Bahia foi fornecido pela BAHIATURSA. Em alguns casos não houre coincidência munćrica. o que demonstra que nem todos os crentos internacionais foram realizaldos no Centro de Convenções da Bahia. Salienti-sc a atipicidade do ano de 1986 qua ndo, para cfeitos estatísticos. a BAHIATURSA obtere dez crentos interniaionalis, c a EMBRATUR considerou apenas oito erentos cm Salvador

Tabela 2 - Eventos x Participantes

\begin{tabular}{|c|c|c|c|c|c|}
\hline \multicolumn{3}{|c|}{ BR.ISIL } & \multicolumn{3}{|c|}{ B.AIILA (C $\therefore$ de Comsempooes) } \\
\hline Ano & Eventos & Participantes & leventos & Participantes & $\%$ \\
\hline 1985 & 91 & 55.865 & ()2 & 1.75() & 4.3 \\
\hline 1986 & 92 & 62.589 & 1) & $7.600)$ & 8,6 \\
\hline 1987 & 98 & 65.374 & ()1 & $1.000)$ & 1.0 \\
\hline 1988 & 98 & 97.352 & 05 & 12.400 & 5,1 \\
\hline 1989 & 109 & 116.756 & ()3 & 1.150 & 2,7 \\
\hline
\end{tabular}

Font: EMBRATUR; BAHIATURRSA

Esta tabela comprova que o turismo de congressos na Bahia, desde 1986 , quando chegou a corresponder $8.6 \%$ dos congressos realizados no Brasil, foi reduzido a um porcentual irrisório de $2.7 \% \mathrm{~cm} 1989$. Além destes, hí outros dados da BAHIATURSA que acrescentam elementos à análise do papel do Centro de Convenções da Bahiai

a) 1986 foi o melhor ano para o Centro de Conveções da Bahia. clıeganndo a ter 29.4()() turistas congressistas, gerando uma receita de $33 .(075$.()()() bilhões de dólares para o Estado:

b) cm relação a 1989. a quantidade de turistas foi redurida em +2\% (199(1) c $53 \%$ (1991)

c) o número de eventos internacionais, de 1986 até hoje, vem se redurindo significativamente, chegando, cm 199()-1991, a igualar-se ao monlento cm que o Centro de Convenções da Bahia foi inaugurado:

d) os crentos nacionais também, desde 1987, vêm se reduzindo, c apresentoll. cm 1991, apenas 11 erentos:

c) os crentos locias são os únicos que têm crescido. Estes dados reveliım que. por ano, há a média de 30 formaturas, com cerca de 1.80() participantes. On scja, no cômputo total, a quantidade de erentos locais é significatii il:

84 f) a média de crentos, no pcriodo de 1979 a 1991, por ano, chega a 3 crentos internacionais, 17 nacionais, 14 regionais c 91 locais.

A média total de crentos por ano é de 125 , com um público médio de 381.787 pessoas, dasquaisapenas 18.056 correspondem aturistas congressistas. Nestes dados da BAHIATURS

investido em promoção turística é muuto reduzido. Sc o CCB tem como um dos objetivos resolver o problcma da sazonalidade do turismo na Baluia, por certo não vem cumprindo esta finalidade, pois os números mostram uma certa insignifieincia nesta áreá.

Para cxistir a captação, a motivação da viagem ć um dado muıto importantc. Segundo dados da BAHIATURSA, cercal de 58\% dos turistas que vêm à Bahia são motivados pelo lazer. Quanto ao turismo de negócios, estc corresponde a $27 \%$ do total dos turistas. Como causì de viagem, participação em congressos e convenções, menos de $10 \%$ têm este motivo.

O decréscimo na captaçĩo de cventos para a Bahia indica problemas no setor. Para a realização, por exemplo, de um cncontro internacional, a captação deveria ser feita, no mínimo, quatro anos antes de sua realização. Isto significa que a captação de congressos deve ser uma atividade constante, c que a descontinuidade da administração pública não deveria afetar csta área. No entanto, esta prática política na Bahia tem trazidopara o setor sérias conscqüiências. No governoBaiano(1986 c 1991), o turismo foi considerado uma atividade de elite, com muito pouco investimento na árca. Esta postura deverá refletir-sc no turismo de congressos, de dois a quatro anos subseqüentes. Esta falta de investimento pode ser observada na Tabcla 3.

Este quadro vem se modificando desde 1992, pois o Setor de Capacitação de Eventos do Centro tem trabalhado ativamente para recuperar os eventos que podem ser rcalizados na Bahia. Faz parte desta política o programa "Viver Bahia" em que o Estado, cm parccria com instituiçõcs privadas do trade turistico, trazautoridades das associações centidades de classe para conheceren a Bahia num final de semana. Com isto os representantes vêcm do que poderão dispor e como poderão aliar trabalho c lazer.

Na tentativa de prevenir ou evitar suscet ibilidadecom aspoliticas públicas em 1990, iniciou-se grande campanha a fim de privatizar o Centro de Convenpões da Bahia, considerando-se a complcxidade para a sua auto-sustcntação c as freqüentes dificuldades do Estado. De acordo com dados da ICCA, mais de 95\% dos Centros de Convenções do mundo trabalham cm déficit, isto quer dizer queo Estado da Bahia não ć o único deficitário. Omotivo varia para cada Ccntro, pois as estnuturas sĩo bastante difcrenciadas, não se justificando homogeneidade $\mathrm{em}$ Suas atividades. Para ilustrar o déficit que ocorre cm todos os Centros, c entre ores o CCB, observe os dados da Tabela 4. 
Tabcla 3 - Despesas com Promoções - BAHIATURSA (198()/1989) - USS mil

\begin{tabular}{|c|c|c|c|}
\hline Anos & $\begin{array}{c}\text { Valor das } \\
\text { despesas }\end{array}$ & $\begin{array}{c}\text { Indice para } \\
1980=100\end{array}$ & $\begin{array}{c}\text { Indice para } \\
1985\end{array}=$ 100 \\
\hline 1980 & 1.248 & 100,0 & - \\
\hline 1981 & 1.744 & 139,7 & $\cdots$ \\
\hline 1982 & 2.257 & 180,9 & $\cdots$ \\
\hline 1983 & 1.458 & 116,8 & $\cdots$ \\
\hline $1984^{a}$ & 1.783 & 142,9 & 100,0 \\
\hline 1985 a & 2.585 & 207,0 & 88,0 \\
\hline $1986^{a}$ & 2.288 & 183,3 & 36,5 \\
\hline 1987 & 943 & 75,6 & 33,8 \\
\hline 1988 & 873 & 70,0 & 18,5 \\
\hline 1989 & 478 & 38,3 & \\
\hline
\end{tabular}

a. Exceto despesas referentes ao P'rojeto de Valorizaçăo da Orla Maritima

Nota: Valores deflacionados pelo IGP-DI e convertidos para dólar taxa de $1989=2,828$ parai ia vend.

Fonte: Bahia: Reconstrução e Integração Dinàmica CPE (1991).

Tabela 4 - Centro de Convenções (la Bahia. Receita próp) ria/despesas com custeco (excluindo pessoal/encargos) - 1986-1990)

\begin{tabular}{|c|c|c|c|c|c|}
\hline \multirow{2}{*}{ Discrininaçāo } & \multicolumn{5}{|c|}{ Anos } \\
\hline & $1986^{a}$ & $1987^{a}$ & $1988^{b}$ & $1989^{b}$ & 199()$^{b}$ \\
\hline (A) Recrita & 7.439 & 24.734 & 159.540 & 1.694 & 18.266 \\
\hline (B) Despesals & 10.597 & 32.975 & 203.943 & 2.385 & 24.880 \\
\hline Diferença (A-B) & $(3.158)$ & $(8.241)$ & $(44.403)$ & $(691)$ & $(6.614)$ \\
\hline$\%$ descoberta & $70 \%$ & $76 \%$ & $79 \%$ & $72 \%$ & $74^{\circ}, 1$ \\
\hline
\end{tabular}

a. Em Cr\$ $1 .(0)(0,()()$

b. Em NCr\$ 1.()()(),()).

Fonte: BAHINTURSA.

Nessals despesas de custeio estão incluidas energia, telefone, agyul. materiais diversos, combustiveis, diárias de pessoal c assistência médica ilos funcionários. Esses dados revelam que, mesmosem incluir a folha de pagamento nais os encargos, a receita do CCB não cobre suas despesas. Outro fator importante a ser considerado para a ocupação do Centrode Convenções da Bahia é que se está distante do eivo Rio-São Paulo, onde a maioria das entidades nacionais. que promovem eventos, está sediada. Ao mesmo tempo, deve-se considerar que há grande rolatividade na realização dos eventos.

Isto leva a admitir, novamente, que o papel da área de captação scrá principalmente função do lobby feito às entidades promotora, da oferta de boas condições de atendimento, aliada a outros fatores, tais como hospedagem c serviços de uma mancira geral.

Tem-se, ainda, a pouca utilização do Centro como equipamento de lazer e cultura da comunidade. Quanto ao lazer, algumas feiras realizadas, anualmentc, ainda atraem pessoas ao Centro. Já no que diz. respeito à cultura, foi necessário que o Teatro Castro Alves parassede funcionar para que o Auditório Yemanjá. que senc também como palco. começasse a receber artistas para shows e espetáculos teatrais.

\section{CONSIDERAÇÕES FINAIS}

O turismo de eventos vem crescendo consideravelmente c assume a posição de destaque entre as três primciras indústrias mundiais. Até 1992, Centro de Convenções da Bahia cra equipamento turístico que colaborava, com o mínimo de seu potencial, para o incremento do turismo de eventos na Bahia. Desde 0 ano passado, com o marketing bem-claborado da BAHIATURSA, cstc tipo de turismo vem crescendo. Como ponto forte deste Centro, destaca-se sua localização, próximo a centro da cidade càs vias de entrada c saída de Salvador.

Mas os problemas existentes têm limitado as captações.

A verticalização ć o grande problema do projeto, pois dificulta bastante a comunicação entre andares c a integração maior de detcrminados eventos. A área de parque c lazer não cxistc. E, apesar de localizar-se próximo ao mar, não se consegue ter um verde que quebre a rigidez da estnıtura de cimento.

Quando a utilização do Centro de Convenções for feita para eventos mais numerosos c populares, scrá necessário um reforço de segurança, a fim de que nãohaja danosao patrimônio. Isto não sendo feito gera uma despesia grande, pelo alto custo de manutenção e posterior recuperação, em razão da depredação costunnciramente efetuada no Centro.

O turismo de eventos na Bahia pode ter um incremento maior, se forem feitas "parcerias" para objetivos diversos, a fimde captar eventos para Salvador. Nesta ação conjunta, deve haver uma preocupação básica dos empresários hoteleiros cm colaborar, pois estes, através dos cventos, conseguem reduzir bastante a sizzonalidade da demanda turistica nos hotćis. 
Uma das opçoes para acabar com a descontinuidade administratisa dá área pública seria criar o Convention Bureau que daria maior independência à atividade.

Atualmente, ć precisocontinuar com a vontade política, que eviste desde 1992, para ampliar os investimentos na captação de eventos.

\section{REFERÊNCIAS BIBLIOGRÁFICAS}

ABBE', James R. 1987. The comention and meetings sector. Its operation and research needs. In [BRI:NT, J.R.Ritchic a G(OIELIDNI:R, Charles R. Tourism and hospitality rese handbook for managers and researches. New York: Ed. John W'iley \& Sons.

[BAIIATURSA. 1981. Anteprojeto sobre mercado internacional de eventos. Salvador.

BURMAN, Grazia c PROSÉRPIO, Renata, 1989. Turismo em Salvador. Salvador: CPE.

COVEL,L(), Amóbio. 1982. Filosofia

KRIPPI:NIOORI, Jost. 1989. Sociologia do turismo. Para uma nova compreensão do lazer e dis viagens. Rio de Janciro: Civilização Brasileira.

TABBARES, Fábio Cárdenas. 1986. C'omercializacion del turismo: determinación y' análisis ck mercados. Mévico: I:d. Trillas. 